\title{
The relationship between anthropometric indicators and walking distance in patients with chronic obstructive pulmonary disease
}

This article was published in the following Dove Press journal:

International Journal of COPD

8 September 2015

Number of times this article has been viewed

\author{
Shu-Chuan Hol,* \\ Min-Fang $\mathrm{Hsu}^{2,3, *}$ \\ Han-Pin Kuo ${ }^{4}$ \\ Jiun-Yi Wang ${ }^{2}$ \\ Li-Fei Chen ${ }^{4}$ \\ Kang-Yun Lee ${ }^{5,6}$ \\ Hsiao-Chi Chuang'
}

'School of Respiratory Therapy, College of Medicine, Taipei Medical University, Taipei, ${ }^{2}$ Department of Healthcare Administration, Asia University, Wufeng, Taichung, ${ }^{3}$ Department of Nursing, Kang-Ning Junior College of Medical Care and Management, Taipei, ${ }^{4}$ Department of Thoracic Medicine, Chang Gung Memorial Hospital, Chang Gung University College of Medicine, Taipei, ${ }^{5}$ Division of Pulmonary Medicine, Department of Internal Medicine, Shuang Ho Hospital, ' $D$ Department of Internal Medicine, School of Medicine, College of Medicine, Taipei Medical University, Taipei, Taiwan

*These authors contributed equally to this work

Correspondence: Shu-Chuan Ho School of Respiratory Therapy, College of Medicine, Taipei Medical University, Number 250, Wuxing St, Taipei, II 03 I, Taiwan

Tel +88622736 I66 I Ext 35I2

Fax +88622739 I| 43

Email shu-chuan@tmu.edu.tw
Background: Exercise intolerance is a major issue affecting many people with COPD. Six-minute walking distance (6MWD) is a widely used indicator of exercise capacity in patients with COPD. The process is strenuous and time-consuming, especially for patients who have muscle wasting. Anthropometric indicators that reflect body lean mass, such as body mass index (BMI), mid-arm circumference (MAC), and calf circumference (CC), may have value in predicting exercise intolerance.

Purpose: This study attempted to determine the abilities of simple anthropometric indicators including BMI, MAC, and CC in reflecting the exercise intolerance of COPD patients.

Methods: We recruited 136 nonhospitalized ambulatory COPD patients without acute conditions from a general hospital in Taiwan. Each subject's BMI, MAC, and CC were measured, and they were examined with pulmonary function tests and a 6-minute walk test.

Results: Among the three anthropometric indicators examined, $\mathrm{CC}$ showed the strongest correlation with the 6MWD, followed by MAC and BMI. CC was also strongly associated with functional capacity, followed by MAC, according to the receiver operating characteristic curves. $\mathrm{CC}$ and MAC, but not BMI, were significantly associated with exercise intolerance according to logistic regression models that controlled for potential confounders.

Conclusion: Among the three variables examined, $\mathrm{CC}$ and walking distance may have the strongest association in COPD patients. CC may have value in serving as an adjunct to 6MWD in evaluating exercise intolerance of patients with COPD.

Keywords: 6-minute walk distance, BMI, calf circumference, COPD, mid-arm circumference

\section{Introduction}

COPD is a major public health problem. In 2020, COPD is predicted to be the fifth leading cause of death in the world. ${ }^{1}$ Exercise intolerance is a major disability in persons with COPD. ${ }^{2,3}$ The disease severely affects their ability to perform activities of daily living and their quality of life., ${ }^{3,4}$ The causes and mechanisms of exercise intolerance in these patients are complex and involve ventilator and respiratory mechanic impairments, gas exchange limitations, and muscle mass reductions in the extremities. ${ }^{5}$ Thus, the ability to perform exercise is an important indicator of the severity of COPD, and an exercise test is an important component in routine clinical assessment of patients with this disease.

The 6-minute walk test (6MWT) is the most commonly used test for rating the functional capacity of persons with COPD. It is a reliable, valid, and responsive test measuring the functional exercise capacity of patients with COPD. To reduce 
the variability between test subjects and to improve the reproducibility in a given individual, the test standard specifies that the $6 \mathrm{MWT}$ must be conducted on a $30 \mathrm{~m}$ straight path. ${ }^{6}$ The $6 \mathrm{MWT}$ measures four functional indicators: 6-minute walking distance (6MWD), self-perceived dyspnea, oxygen saturation, and heart rate. ${ }^{7}$ Among these indicators, $6 \mathrm{MWD}$ is probably the most frequently used or studied. A 6MWD $<350 \mathrm{~m}$ is often considered the threshold for poor prognosis. ${ }^{8,9}$

In addition to the 6MWT space consideration, we should also consider that older patients with severe COPD and dyspnea with exercise have some limitations. Some studies found that the exercise capacity of COPD patients is related to lung function as well as anthropometric indicators such as body mass index (BMI), fat-free mass index, and status of systemic inflammation. ${ }^{10}$ The 6MWD and dyspnea Borg scores are associated with fat-free mass index ${ }^{11}$ and BMI and are positively associated with exercise capacity in COPD patients. ${ }^{11,12}$ In non-COPD elderly population, mid-arm circumference (MAC) and calf circumference (CC) have been observed to be better indicators of physical functional ability than BMI. ${ }^{13}$ Bonnefoy et al have suggested that circumferences of the extremities may provide valuable information on muscle-related disabilities and physical functional capacity in these patients. ${ }^{14}$ Recent studies have also shown that circumferences of the extremities, such as CC and MAC, might be better indicators of exercise capacity. ${ }^{15,16}$

However, the ability of these anthropometric indicators to reflect exercise capacity in COPD patients has not been examined. Thus, this study attempted to examine the anthropometric indicators and 6MWT in relation to the assessment of exercise capacity in patients with COPD.

\section{Methods}

\section{Study design and patients}

We conducted a cross-sectional study in persons with COPD who were recruited from the pulmonary outpatient unit of a medical center in northern Taiwan from November 2009 to August 2011. The diagnosis of COPD and the stage of the severity of the disease were based on the 2007 version of the Global Initiative for Chronic Obstructive Lung Disease guidelines. ${ }^{2}$ COPD patients with a forced expiratory volume in 1 second $\left(\mathrm{FEV}_{1}\right) /$ forced vital capacity ratio of $<70 \%$ of the predicted value and aged 40-85 years were qualified to participate. Exclusion criteria included acute infection or acute exacerbation within 3 months prior to the study (no requirement for antibiotic or oral corticosteroid therapy and no change in respiratory symptoms), requirement for oxygen therapy during exercise (because these patients were different at baseline on the 6MWT), and severe systemic disease (malignancy, systemic lupus erythematosus, end-stage renal disease, and severe liver cirrhosis). A total of 136 patients (131 men and five women) were qualified and agreed to participate. All participants were ambulatory, in stable condition, and undergoing standard pharmacological treatment for COPD. The study protocol was approved by the Ethics Committee of the Chang-Gung Memorial Hospital (98-3601B and 100-0002C), and all subjects gave written informed consent before participating in the study.

\section{Procedures and measurements}

Each patient was interviewed face-to-face by well-trained researchers (Ho and $\mathrm{Hsu}$ ) to elicit demographic, lifestyle, and disease-related data. The participants' weight, height, MAC, and CC were measured, and all patients' physical functional capacity was evaluated by a well-trained therapist (Ho or Chen) with the 6MWT and pulmonary function tests.

Weight, height, MAC, and CC were measured according to standard methods. ${ }^{17}$ Body weight was measured to the nearest $0.1 \mathrm{~kg}$ with the subjects standing barefoot with light indoor clothing. Height was measured to the nearest $0.1 \mathrm{~cm}$. BMI was calculated according to $\mathrm{kg} / \mathrm{m}^{2}$. MAC and $\mathrm{CC}$ were measured to the nearest $0.1 \mathrm{~cm}$ with a flexible but non-stretching measuring tape ${ }^{17} \mathrm{MAC}$ was measured at the midpoint of the nondominant arm (between the olecranon and acromion) and $\mathrm{CC}$ was measured at the largest point of the left calf in a sitting position.

Pulmonary function tests were performed with a Spiroanalyzer ST-250 (Fukuda Sangyo Co Ltd., Nagareyama City, Chiba, Japan) after a 10-minute rest. The best of at least three reproducible $\mathrm{FEV}_{1}$ and forced vital capacity values (with a difference within $200 \mathrm{~mL}$ or less than 5\%) were used.

Exercise capacity was assessed with the 6MWT according to the American Thoracic Society guidelines. The scale was validated ${ }^{18}$ and shown to be reliable ${ }^{19}$ in evaluating the exercise capacity of persons with COPD. All patients were instructed to walk as far as possible but were allowed to stop and rest during the test. ${ }^{6}$ Oxygen saturation and pulse rate were recorded using a continuous finger-adapted pulse oximeter. Additionally, at the beginning and end of the 6MWT, the difference in exertion was assessed with the modified Borg scale ${ }^{20}$ by rating perceived exertion based on breathlessness. We used a ten-point scale with a nonlinear scaling scheme using descriptive terms to anchor responses, which is a commonly used format. ${ }^{21}$ 


\section{Statistical analysis}

The results were statistically analyzed with SPSS for Windows 19.0 (SPSS Inc., Chicago, IL, USA). Descriptive data are expressed as the mean \pm standard deviation or percentage. According to the Kolmogorov-Smirnov test, FEV, MAC, and $\mathrm{CC}$ were normally distributed $(P>0.20)$, but BMI and 6MWD were not normally distributed $(P<0.05)$. Spearman's correlation was used to evaluate the strength of the relationship between various anthropometric and pulmonary function indicators with the 6MWD. We used the sample size calculation for logistic regression with PASS 14 statistical software to retrospectively estimate the results of approximately 110 cases. The abilities of BMI, MAC, and CC in discriminating exercise capacity were analyzed with receiver operating characteristic (ROC) curves using the $6 \mathrm{MWD}(<350 \mathrm{~m})$ as the reference standard. The areas under the curve (AUCs) of the ROC curves were determined. A larger AUC (maximum is 1) indicates better predictive ability. The association of $\mathrm{BMI}, \mathrm{MAC}$, and $\mathrm{CC}$ with the 6MWD was also analyzed with a multivariate logistic regression analysis. All models were controlled for possible confounders (age and $\mathrm{FEV}_{1}$ ). Statistical significance for all evaluations was set at $\alpha=0.05$.

\section{Results}

Table 1 shows the characteristics of the participants. The subjects averaged $72.4 \pm 7.5$ years in age, $23.5 \pm 15.0 \mathrm{~kg} / \mathrm{m}^{2}$ in BMI, 26.4 $\pm 3.5 \mathrm{~cm}$ in MAC, and $32.9 \pm 3.5 \mathrm{~cm}$ in CC. Over half of the subjects had mild or moderate COPD, approximately $1 / 3$ of the subjects $(31.6 \%$ ) had severe COPD, and only $16.9 \%$

Table I Characteristics of I 36 patients with COPD

\begin{tabular}{ll}
\hline Variables & Mean \pm standard deviation \\
\hline Age (year) & $72.41 \pm 7.47$ \\
Sex, $M / F(\mathrm{n})$ & $131 / 5$ \\
Body mass index $\left(\mathrm{kg} / \mathrm{m}^{2}\right)$ & $23.47 \pm 15.00$ \\
Mid-arm circumference $(\mathrm{cm})$ & $26.37 \pm 3.54$ \\
Calf circumference $(\mathrm{cm})$ & $32.94 \pm 3.48$ \\
FEV, $(\mathrm{L} / \mathrm{min})$ & $1.02 \pm 0.39$ \\
FEV ${ }_{1}$ (\% of prediction) & $51.68 \pm 20.82$ \\
Forced vital capacity $(\mathrm{L} / \mathrm{min})$ & $2.43 \pm 5.48$ \\
Forced vital capacity $(\%$ of prediction) & $70.60 \pm 19.22$ \\
$6 \mathrm{MWD}(\mathrm{m})^{\mathrm{b}}$ & $382.49 \pm 90.33$ \\
$\mathrm{O}_{2}$ saturation at rest $(\%)$ & $95.09 \pm 2.32$ \\
Borg score, at rest & $0.82 \pm 1.23$ \\
Heart rate, at rest $(\mathrm{bpm})$ & $90.54 \pm 16.68$ \\
\hline
\end{tabular}

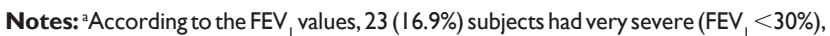
$43(31.6 \%)$ subjects had severe $(\mathrm{FEV},>50 \%$ and $\leq 30 \%)$, and $70(51.5 \%)$ subjects

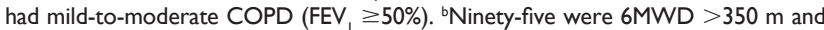
41 were $<350 \mathrm{~m}$.

Abbreviations: 6MWD, 6-minute walking distance; $F E V_{\text {, }}$, forced expiratory volume in I second; FVC, forced vital capacity; M, male; F, female.
Table 2 Spearman's correlation coefficients ( $r$ ) of BMI, MAC, and $\mathrm{CC}$ with items in 6-minute walk distance and $\mathrm{FEV}$, of I 36 patients with COPD

\begin{tabular}{lll}
\hline Indicators & 6MWD & FEV \\
\hline BMI & $0.252^{* *}$ & $0.255^{* *}$ \\
MAC & $0.30 I^{* *}$ & $0.207^{*}$ \\
CC & $0.426^{* *}$ & $0.17 I^{*}$ \\
FEV & $0.177^{*}$ & - \\
\hline
\end{tabular}

Note: $* P<0.05$ and $* * P<0.01$ based on Spearman's correlation test.

Abbreviations: 6MWD, 6-minute walk distance; BMI, body mass index; CC, calf circumference; $\mathrm{FEV}_{\text {, }}$, forced expiratory volume in I second; MAC, mid-arm circumference.

of the subjects had very severe COPD. Approximately $2 / 3$ of the subjects (95) had a 6MWD result of $>350 \mathrm{~m}$, and 41 of the subjects had a result of $<350 \mathrm{~m}$. The average $\mathrm{O}_{2}$ saturation was $95.25 \%$ at rest. The average Borg score was $0.85 \pm 1.3$ at rest. The average heart rate was $90.5 \pm 16.7 \mathrm{bpm}$ at rest.

Table 2 shows Spearman's correlation coefficients of the anthropometric indicators (BMI, CC, and MAC) and $\mathrm{FEV}_{1}$ with 6MWD; all were significantly correlated with BMI $(r=0.252, P<0.01)$, MAC $(r=0.301, P<0.01), \mathrm{CC}(r=0.426$, $P<0.01)$, and $\mathrm{FEV}_{1}(r=0.177, P<0.05)$. Similarly, the anthropometric indicators with $\mathrm{FEV}_{1}$ were all significantly correlated with BMI, MAC, and CC.

Table 3 shows the logistic regression analysis of the association of various variables with 6MWD using $350 \mathrm{~m}$ as a threshold. Using a base model that controlled for age and $\mathrm{FEV}_{1}$, model I explained between 10.4\% (Cox \& Snell) and $14.7 \%$ (Nagelkerke) of the variance in 6MWD in patients with COPD. BMI (odds ratio $[\mathrm{OR}]=0.89,95 \%$ confidence interval $[\mathrm{CI}]=0.79-1.00, P=0.050)$ did not show a significant association with impaired 6MWD. Model II explained between 14.1\% (Cox \& Snell) and 19.7\% (Nagelkerke) of the variance in 6MWD in patients with COPD. $\mathrm{MAC}(\mathrm{OR}=0.82$, $95 \% \mathrm{CI}=0.71-0.93, P=0.003$ ) showed a significant association with impaired 6MWD. Model III explained between $16.3 \%$ (Cox \& Snell) and 23.0\% (Nagelkerke) of the variance in 6MWD in patients with COPD. CC (OR $=0.79,95 \%$ $\mathrm{CI}=0.68-0.90, P=0.001)$ showed a significant association with impaired 6MWD.

Figure 1 shows the ability of $\mathrm{BMI}, \mathrm{MAC}$, and $\mathrm{CC}$ in differentiating impaired 6MWD $(<350 \mathrm{~m})$ with the ROC curves. The AUCs were 0.675 (0.514-0.776, $P=0.001), 0.709$ $(0.616-0.802, P=0.000)$, and $0.758(0.669-0.847, P=0.000)$ for BMI, MAC, and CC, respectively.

\section{Discussion}

The results show that among the three anthropometric indicators examined, $\mathrm{CC}$ demonstrated the strongest association 
Table 3 Multivariate binary logistic regression analysis of the association of various variables with impaired $6 \mathrm{MWD}(<350 \mathrm{~m})$ in I36 patients with COPD

\begin{tabular}{|c|c|c|c|c|c|c|}
\hline \multirow[t]{2}{*}{ Variables } & \multicolumn{2}{|l|}{ Model I: BMI } & \multicolumn{2}{|l|}{ Model II: MAC } & \multicolumn{2}{|l|}{ Model III: CC } \\
\hline & OR (95\% Cl) & $P$-value & OR $(95 \% \mathrm{Cl})$ & $P$-value & OR $(95 \% \mathrm{Cl})$ & $P$-value \\
\hline$\overline{\text { Age }}$ & $1.06(0.99-1.32)$ & 0.064 & $1.05(0.98-I .12)$ & 0.162 & $1.04(0.98-1.13)$ & 0.219 \\
\hline $\mathrm{FEV}_{1}$ & $0.97(0.95-0.99)$ & 0.029 & $0.98(0.95-1.00)$ & 0.056 & $0.98(0.95-1.00)$ & 0.080 \\
\hline BMI & $0.89(0.79-1.00)$ & 0.050 & - & - & - & - \\
\hline MAC & - & - & $0.82(0.7 \mathrm{I}-0.93)$ & 0.003 & - & - \\
\hline $\mathrm{CC}$ & - & - & - & - & $0.79(0.68-0.90)$ & 0.001 \\
\hline
\end{tabular}

Notes: Model I: -2 likelihood log =151.55; Cox \& Snell $R^{2}=0.104$; Nagelkerke $R^{2}=0.147$; Model II: -2 likelihood log $=145.88$; Cox \& Snell $R^{2}=0.141$; Nagelkerke $R^{2}=0.199$; Model III: -2 likelihood log =142.28; Cox \& Snell $R^{2}=0.163$; Nagelkerke $R^{2}=0.2$.

Abbreviations: 6MWD, 6-minute walk distance; $\mathrm{BMI}$, body mass index; $\mathrm{CC}$, calf circumference; $\mathrm{Cl}$, confidence interval; $\mathrm{FEV}$, forced expiratory volume in I second; $\mathrm{MAC}$, mid-arm circumference; OR, odds ratio.

with the functional indicators, especially the 6MWD, compared to MAC and BMI. CC and MAC are the indicators that significantly predicted impaired 6MWD according to the regression analysis, and these factors may be capable to predict those with impaired 6MWD, according to the ROC analysis.

\section{Association with exercise capacity}

Enright et al established reference sex-specific equations to predict $6 \mathrm{MWD}$ in healthy adults: for men:

$$
\begin{aligned}
6 \mathrm{MWD}= & \left(7.57 \times \text { height }_{\mathrm{cm}}\right)-(5.02 \times \text { age })- \\
& \left(1.76 \times \text { weight }_{\mathrm{kg}}\right)-309 \mathrm{~m}
\end{aligned}
$$

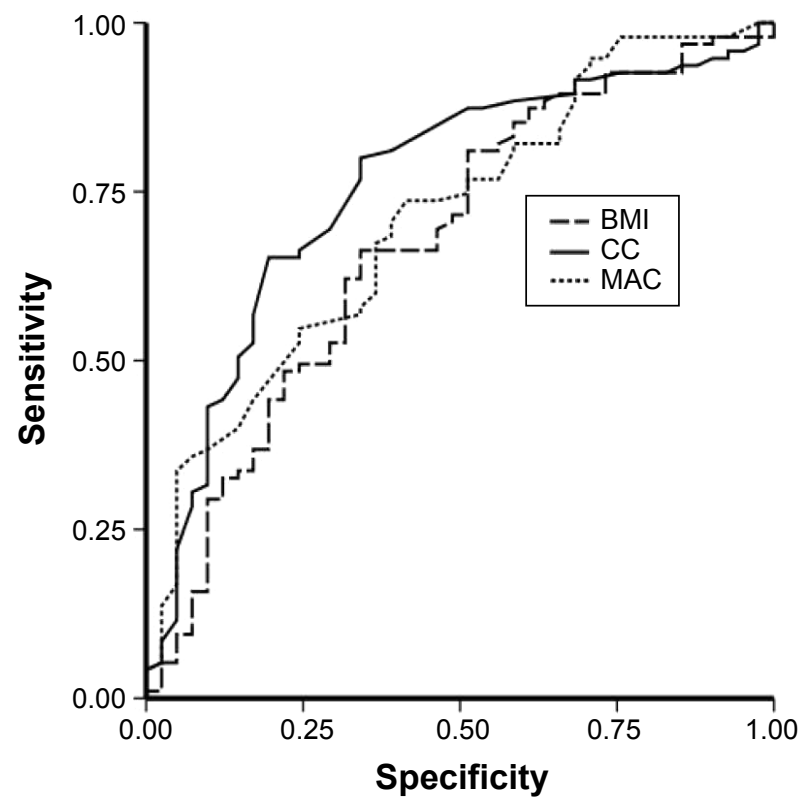

Figure I The receiver operating characteristic curves for BMI, MAC, and CC in persons with COPD, using $350 \mathrm{~m}$ of 6-minute-walking distance as the reference. Note: Areas under the curve for BMI, MAC, and CC were $0.675(95 \%$ confidence interval $=0.5 \mathrm{I} 4-0.776, P=0.00 \mathrm{I}), 0.709(0.616-0.802, P=0.000)$, and $0.758(0.669-0.847$, $P=0.000$ ), respectively.

Abbreviations: BMI, body mass index; CC, calf circumference; MAC, mid-arm circumference. and for women:

$$
\begin{aligned}
6 \mathrm{MWD}= & \left(2.11 \times \text { height }_{\mathrm{cm}}\right)-(5.78 \times \text { age })- \\
& \left(2.29 \times \text { weight }_{\mathrm{kg}}\right)+667 \mathrm{~m}
\end{aligned}
$$

The 6MWD is reduced by several types of diseases, including obstructive lung disease, heart disease, and neuromuscular disease. ${ }^{23}$ The determinants of poor 6MWD are complex and depend on both physical and psychological factors, and a poor 6MWD (<350 meters) result has prognostic value in identifying high-risk patients with COPD. ${ }^{24}$ Therefore, in this study, we used the 6MWD (350 m) to define an impairment of functional capacity.

BMI has been demonstrated to influence walking distance in healthy subjects. ${ }^{22}$ Previous studies have shown that patients with a low BMI have lower exercise capacity on submaximal and maximal exercise tests, ${ }^{11,25,26}$ and that low $\mathrm{BMI}$ is an independent indicator of poor prognosis in persons with COPD. However, the present study showed that BMI is a much weaker indicator or functional indicator compared to MAC, particularly compared to CC in persons with COPD. Our finding confirms the findings of Ischaki et $\mathrm{al}^{11}$ in which BMI was not effective in differentiating various COPD stages. Soler-Cataluña et $\mathrm{al}^{27}$ also showed that in persons with COPD, mid-arm muscle area is a better predictor of mortality than BMI. ${ }^{27}$ Villaça et $\mathrm{al}^{28}$ found that an anthropometrically based method of estimating leg lean volume had high specificity and sensitivity in identifying peripheral muscle function in persons with depleted and nondepleted COPD. Patients with low leg lean volume had significantly lower exercise capacity and muscle performance than their normal counterparts. Lean body mass in legs has been observed to be a significant predictor of maximal exercise performance in patients with mild-to-moderate airflow limitation. ${ }^{29}$

The predictive ability of MAC is not as strong as CC. This difference is probably because the degree of functional impairment between the upper and lower limbs 
is different in persons with COPD. Persons with COPD report more dyspnea during arm exercise compared to leg exercise. ${ }^{30,31}$ A major cause of dyspnea is dynamic hyperinflation, which is caused by airflow limitations as well as an increase in ventilation. ${ }^{30,32}$ Lower-limb muscles appear to be associated with muscle endurance and daily functional performance. ${ }^{31}$

In the present study, BMI, MAC, and CC were all significantly correlated with $\mathrm{FEV}_{1}$. However, after adjusting for potential confounders, MAC and CC were not significantly associated with $\mathrm{FEV}_{1}$ in multivariate logistic regression models. Our results support the findings of others, ${ }^{33-35}$ suggesting that $\mathrm{FEV}_{1}$ is not independently associated with 6MWD in COPD.

\section{Significance of CC in COPD}

After controlling for age and $\mathrm{FEV}_{1}$, the results of three models using Nagelkerke measure of variance in 6MWD in patients with COPD were not high (0.147-0.23). However, in model III CC, $R^{2}$ was higher than that in model II MAC and model I BMI. The results of the present study may be affected because some important factors were not included in the models. In the study by Britto et al approximately $62 \%$ of the variance was explained by sex, age, height, and change in heart rate during the test to predict the 6MWD in Brazilian subjects. ${ }^{36}$ The present study suggests that $\mathrm{CC}$ is more effective than BMI or MAC in predicting exercise tolerance in persons with COPD. Lower-limb muscle atrophy is relatively common in persons with $\mathrm{COPD}$, ranging from $21 \%$ to $45 \%$, depending on the population and its operational definition. ${ }^{37,38}$ Muscle atrophy can even be found in persons with COPD with normal body weight. ${ }^{37}$ Thus, it is conceivable that under some conditions, $\mathrm{CC}$ atrophy might be a factor limiting the exercise capability in persons with COPD. In non-COPD individuals, a larger $\mathrm{CC}$ is protective against physical functional decline. ${ }^{39} \mathrm{CC}$ is a pertinent nutritional marker compared to other anthropometric indicators. ${ }^{40,41}$

$\mathrm{CC}$ is a better indicator of body muscle mass because our legs contain over half of the muscle mass of the body and a decrease in walking activity can occur due to functional decline or long-term illness. ${ }^{15}$ It is probable that long-term deconditioning could be caused by sedentary lifestyle in these patients as severe COPD is associated with greater dyspnea sensation and exercise-induced oxygen desaturation. ${ }^{42}$

Taken together, the results of the present study indicate that $\mathrm{CC}$ is highly associated with exercise tolerance in persons with COPD and it might be of value in predicting exercise intolerance in these patients. $\mathrm{CC}$ is highly accessible and simple to measure.

\section{Limitations of the study}

This study has some limitations. First, the study sample size was small and participants were drawn from one hospital; therefore, the results may not reflect the entire spectrum of patients with COPD. Second, there was a disproportionate number of men compared to women in this study. The applicability of study results to female subjects requires further investigation. Third, the present study involves only ambulatory patients with COPD. The applicability of the study results to persons with more severe COPD requires further investigation. Finally, the study could also benefit from using more elaborate body-composition measuring techniques, such as dual radiograph absorptiometry, to measure body lean mass.

\section{Conclusion}

The results suggest that among the three anthropometric indicators examined, $\mathrm{CC}$ is highly correlated with walking ability and can predict exercise capacity in persons with COPD. CC is accessible, non invasive, and easy to measure. It may serve as an alternative or adjunct to 6MWD in rating the physical functional capacity of persons with COPD.

\section{Acknowledgments}

The authors wish to thank the patients and personnel of the hospital unit for their cooperation during the course of this study. The study was supported by a grant from the Chang Gung Memorial Hospital (CMRPG391921), Ministry of Science and Technology (MOST 103-2314-B-038-066), and the Taipei Medical University (TMU102-AE1-B45 and 104TMU-SHH-24). All authors read and approved the final version of the manuscript.

\section{Disclosure}

The authors report no conflicts of interest in this work.

\section{References}

1. Vestbo J, Hurd SS, Agusti AG, et al. Global strategy for the diagnosis, management, and prevention of chronic obstructive pulmonary disease: GOLD executive summary. Am J Respir Crit Care Med. 2013;187:347-365.

2. Rabe KF, Hurd S, Anzueto A, et al. Global strategy for the diagnosis, management, and prevention of chronic obstructive pulmonary disease: GOLD executive summary. Am J Respir Crit Care Med. 2007;176:532-555.

3. Bossenbroek L, de Greef MH, Wempe JB, Krijnen WP, Ten Hacken NH. Daily physical activity in patients with chronic obstructive pulmonary disease: a systematic review. COPD. 2011;8:306-319.

4. van Gestel AJ, Clarenbach CF, Stowhas AC, et al. Prevalence and prediction of exercise-induced oxygen desaturation in patients with chronic obstructive pulmonary disease. Respiration. 2012;84(5):353-359.

5. Pepin V, Saey D, Laviolette L, Maltais F. Exercise capacity in chronic obstructive pulmonary disease: mechanisms of limitation. COPD. 2007; 4:195-204

6. ATS Committee on Proficiency Standards for Clinical Pulmonary Function Laboratories. ATS statement: guidelines for the six-minute walk test. Am J Respir Crit Care Med. 2002;166:111-117. 
7. Enright PL. The six-minute walk test. Respir Care. 2003;48:783-785.

8. Cote CG, Casanova C, Marin JM, et al. Validation and comparison of reference equations for the 6-min walk distance test. Eur Respir J. 2008;31:571-578.

9. Spruit MA, Watkins ML, Edwards LD, et al. Determinants of poor 6-min walking distance in patients with COPD: the ECLIPSE cohort. Respir Med. 2010;104:849-857.

10. Hallin R, Janson C, Arnardottir RH, et al. Relation between physical capacity, nutritional status and systemic inflammation in COPD. Clin Respir J. 2011;5:136-142.

11. Ischaki E, Papatheodorou G, Gaki E, Papa I, Koulouris N, Loukides S. Body mass and fat-free mass indices in COPD: relation with variables expressing disease severity. Chest. 2007;132:164-169.

12. Lan CC, Su CP, Chou LL, Yang MC, Lim CS, Wu YK. Association of body mass index with exercise cardiopulmonary responses in lung function-matched patients with chronic obstructive pulmonary disease. Heart Lung. 2012;41:374-381.

13. Tsai AC, Lai MC, Chang TL. Mid-arm and calf circumferences (MAC and $\mathrm{CC}$ ) are better than body mass index (BMI) in predicting health status and mortality risk in institutionalized elderly Taiwanese. Arch Gerontol Geriatr. 2012;54:443-447.

14. Bonnefoy M, Jauffret M, Jusot JF. Muscle power of lower extremities in relation to functional ability and nutritional status in very elderly people. J Nutr Health Aging. 2007;11:223-228

15. Chumlea WC. Is the MNA valid in different populations and across practice settings? $J$ Nutr Health Aging. 2006;10:524-527; discussion 527-533.

16. Sanchez FF, Faganello MM, Tanni SE, et al. Anthropometric midarm measurements can detect systemic fat-free mass depletion in patients with chronic obstructive pulmonary disease. Braz J Med Biol Res. 2011; 44:453-459.

17. Lee RD, Nieman DC. Assessment of the hospitalized patient. In Nutritional Assessment, 3rd ed., 2003; 216-250, Chapter 7; RD Lea and DC Nieman, editors. New York: McGraw-Hill 2003.

18. Butland RJ, Pang J, Gross ER, Woodcock AA, Geddes DM. Two-, six-, and 12-minute walking tests in respiratory disease. Br Med J (Clin Res Ed). 1982;284:1607-1608.

19. Kervio G, Carre F, Ville NS. Reliability and intensity of the six-minute walk test in healthy elderly subjects. Med Sci Sports Exerc. 2003;35:169-174.

20. American Thoracic Society; American College of Chest Physicians. ATS/ACCP Statement on cardiopulmonary exercise testing. Am J Respir Crit Care Med. 2003;167:211-277.

21. O'Donnell DE. Breathlessness in patients with chronic airflow limitation. Mechanisms and management. Chest. 1994;106:904-912.

22. Enright PL, Sherrill DL. Reference equations for the six-minute walk in healthy adults. Am J Respir Crit Care Med. 1998;158:1384-1387.

23. Guyatt GH, Sullivan MJ, Thompson PJ, et al. The 6-minute walk: a new measure of exercise capacity in patients with chronic heart failure. Can Med Assoc J. 1985;132:919-923.

24. Spruit MA, Polkey MI, Celli B, et al. Predicting outcomes from 6-minute walk distance in chronic obstructive pulmonary disease. $J$ Am Med Dir Assoc. 2012;13:291-297.

25. Celli BR, Cote CG, Marin JM, et al. The body-mass index, airflow obstruction, dyspnea, and exercise capacity index in chronic obstructive pulmonary disease. $N$ Engl J Med. 2004;350:1005-1012.
26. Kobayashi A, Yoneda T, Yoshikawa M, et al. The relation of fat-free mass to maximum exercise performance in patients with chronic obstructive pulmonary disease. Lung. 2000;178:119-127.

27. Soler-Cataluña JJ, Sánchez-Sánchez L, Martínez-García MA, Sánchez PR, Salcedo E, Navarro M. Mid-arm muscle area is a better predictor of mortality than body mass index in COPD. Chest. 2005;128:2108-2115.

28. Villaça DS, Lerario MC, dal Corso S, et al. Clinical value of anthropometric estimates of leg lean volume in nutritionally depleted and non-depleted patients with chronic obstructive pulmonary disease. Br J Nutr. 2008;100:380-386.

29. Yoshikawa M, Yoneda T, Takenaka H, et al. Distribution of muscle mass and maximal exercise performance in patients with COPD. Chest. 2001;119:93-98.

30. Martinez FJ, Couser JI, Celli BR. Respiratory response to arm elevation in patients with chronic airflow obstruction. Am Rev Respir Dis. 1991; 143:476-480.

31. Miranda EF, Malaguti C, Corso SD. Peripheral muscle dysfunction in COPD: lower limbs versus upper limbs. J Bras Pneumol. 2011;37: 380-388. English, Portuguese.

32. Porto EF, Castro AA, Velloso M, Nascimento O, Dal Maso F, Jardim JR. Exercises using the upper limbs hyperinflate COPD patients more than exercises using the lower limbs at the same metabolic demand. Monaldi Arch Chest Dis. 2009;71:21-26.

33. Wijkstra PJ, TenVergert EM, van der Mark TW, et al. Relation of lung function, maximal inspiratory pressure, dyspnoea, and quality of life with exercise capacity in patients with chronic obstructive pulmonary disease. Thorax. 1994;49:468-472.

34. Foglio K, Carone M, Pagani M, Bianchi L, Jones PW, Ambrosino N. Physiological and symptom determinants of exercise performance in patients with chronic airway obstruction. Respir Med. 2000;94:256-263.

35. Bauerle O, Chrusch CA, Younes M. Mechanisms by which COPD affects exercise tolerance. Am J Respir Crit Care Med. 1998;157:57-68.

36. Britto RR, Probst VS, de Andrade AF, et al. Reference equations for the six-minute walk distance based on a Brazilian multicenter study. Braz J Phys Ther. 2013;17:556-563.

37. Vermeeren MA, Creutzberg EC, Schols AM, et al. Prevalence of nutritional depletion in a large out-patient population of patients with COPD. Respir Med. 2006;100:1349-1355.

38. Schols AM, Soeters PB, Dingemans AM, Mostert R, Frantzen PJ, Wouters EF. Prevalence and characteristics of nutritional depletion in patients with stable COPD eligible for pulmonary rehabilitation. Am Rev Respir Dis. 1993;147:1151-1156.

39. Reid KF, Naumova EN, Carabello RJ, Phillips EM, Fielding RA. Lower extremity muscle mass predicts functional performance in mobilitylimited elders. J Nutr Health Aging. 2008;12:493-498.

40. Bonnefoy M, Jauffret M, Kostka T, Jusot JF. Usefulness of calf circumference measurement in assessing the nutritional state of hospitalized elderly people. Gerontology. 2002;48:162-169.

41. Vellas B, Guigoz Y, Baumgartner M, Garry PJ, Lauque S, Albarede JL. Relationships between nutritional markers and the mini-nutritional assessment in 155 older persons. $J$ Am Geriatr Soc. 2000;48:1300-1309.

42. Jenkins S, Čečins N. Six-minute walk test: observed adverse events and oxygen desaturation in a large cohort of patients with chronic lung disease. Intern Med J. 2011;41:416-422.
International Journal of COPD

\section{Publish your work in this journal}

The International Journal of COPD is an international, peer-reviewed journal of therapeutics and pharmacology focusing on concise rapid reporting of clinical studies and reviews in COPD. Special focus is given to the pathophysiological processes underlying the disease, intervention programs, patient focused education, and self management protocols.
Dovepress

This journal is indexed on PubMed Central, MedLine and CAS. The manuscript management system is completely online and includes a very quick and fair peer-review system, which is all easy to use. Visit http://www.dovepress.com/testimonials.php to read real quotes from published authors. 